Supporting information for

\title{
Preparation of Organometal Halide Perovskite Photonic Crystal Films for Potential Optoelectronic Applications
}

Stefan Schünemann ${ }^{\mathrm{a}}$, Kun Chen ${ }^{\mathrm{a}}$, Sarah Brittman ${ }^{\mathrm{b}}$, Erik Garnett ${ }^{\mathrm{b}}$, Harun Tüysüz ${ }^{\mathrm{a} *}$

\footnotetext{
${ }^{a}$ Max-Planck-Institut für Kohlenforschung, Kaiser-Wilhelm-Platz 1, 45470 Mülheim an der Ruhr, Germany

${ }^{\mathrm{b}}$ Center for Nanophotonics, FOM Institute AMOLF, Science Park 104, Amsterdam 1098 $\mathrm{XG}$, The Netherlands

*Corresponding author: tueysuez@kofo.mpg.de
} 


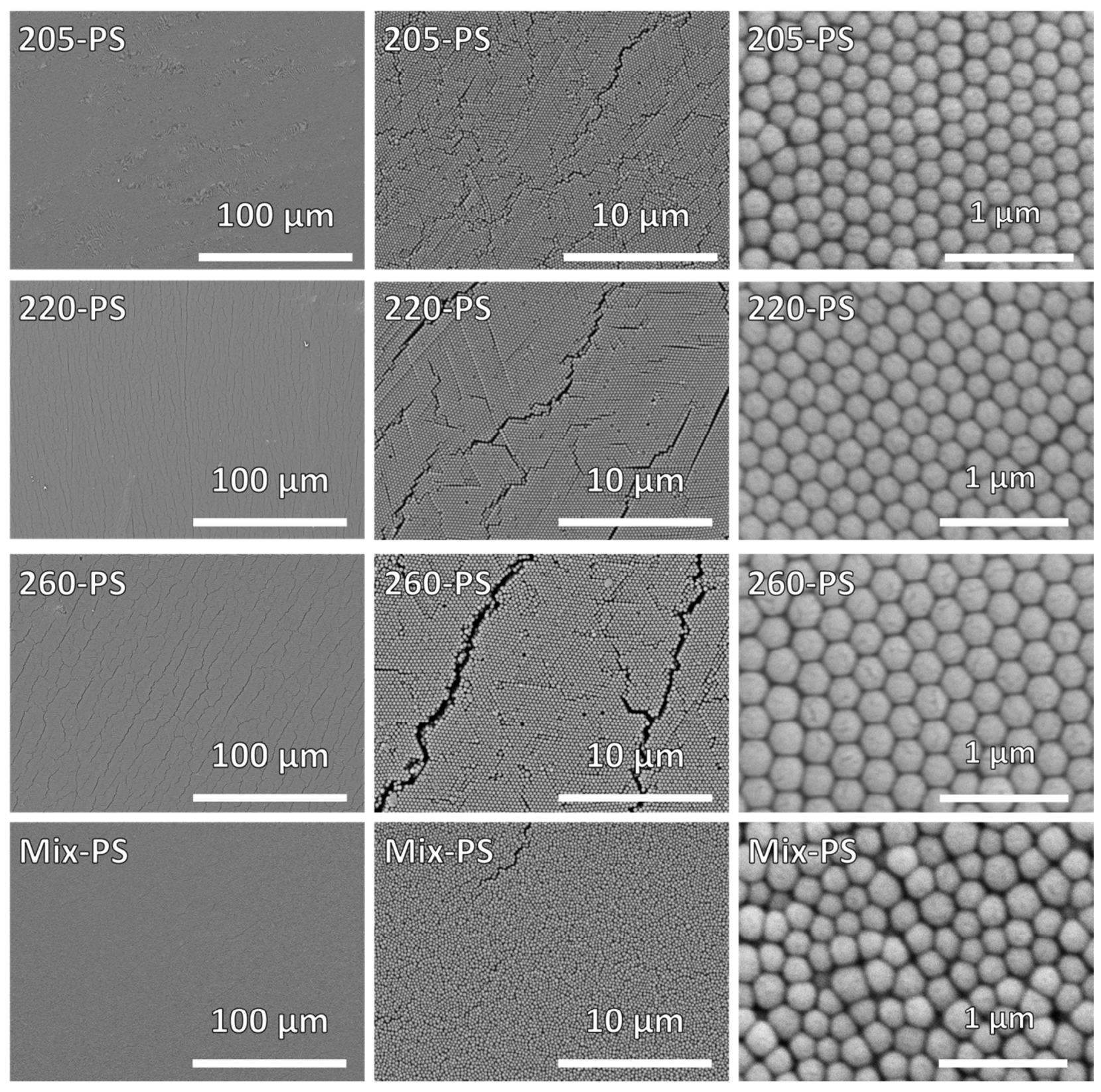

Figure S1: Representative SEM images of 205-PS, 220-PS, 260-PS, and Mix-PS at different magnifications.
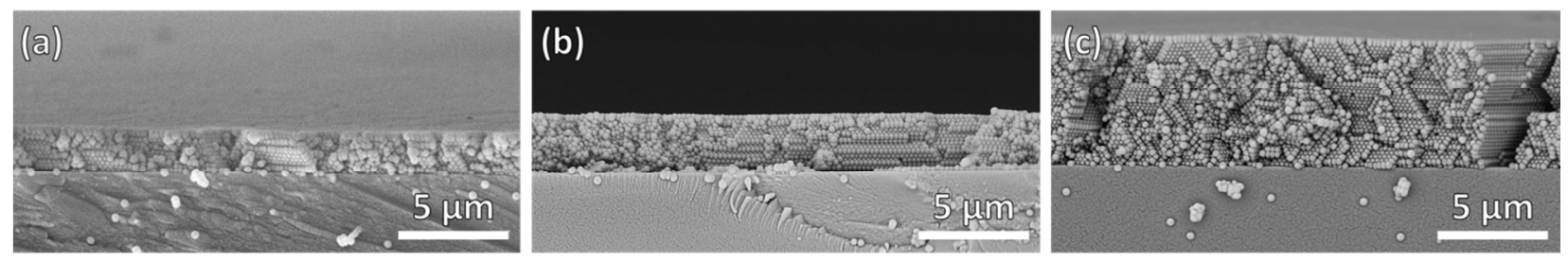

Figure S2: Representative cross-section SEM images of 220-PS with thicknesses of $2 \mu \mathrm{m}(\mathrm{a})$, $3 \mu \mathrm{m}(\mathrm{b})$, and $6 \mu \mathrm{m}$ (c). 

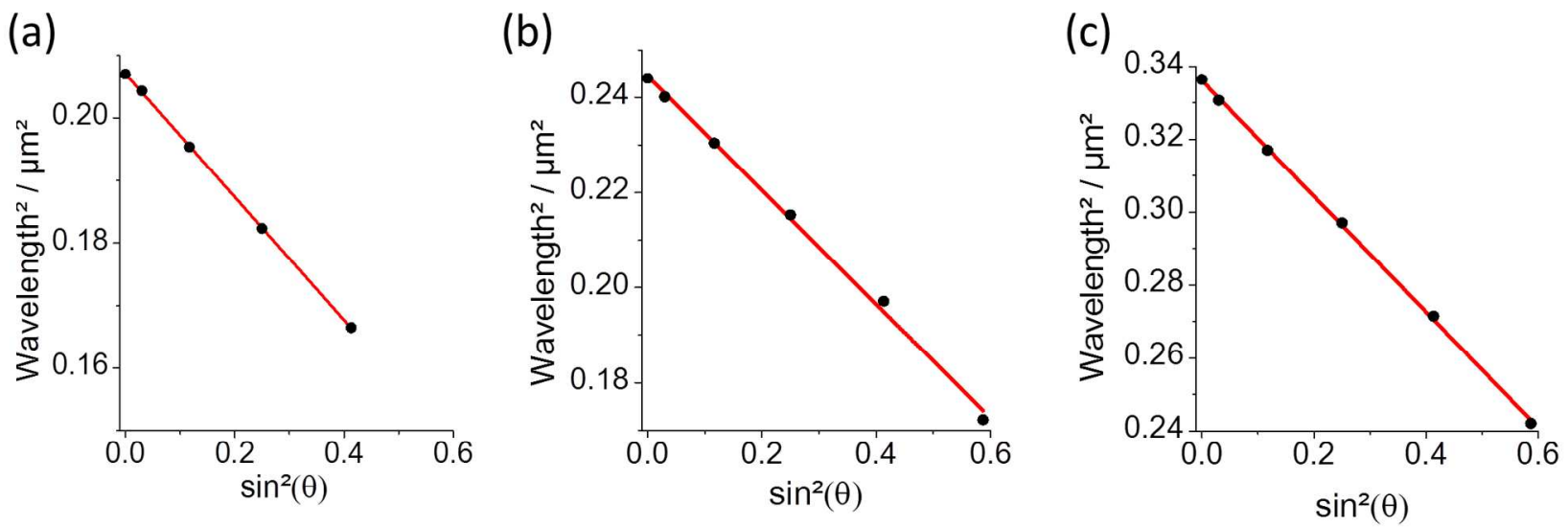

Figure S3: Square of the wavelength at the stop band maximum as a function of the square sine of the incident light (black circles) together with linear regression lines (red line) of 205-PS (a), 220-PS (b), and 260-PS (c). 

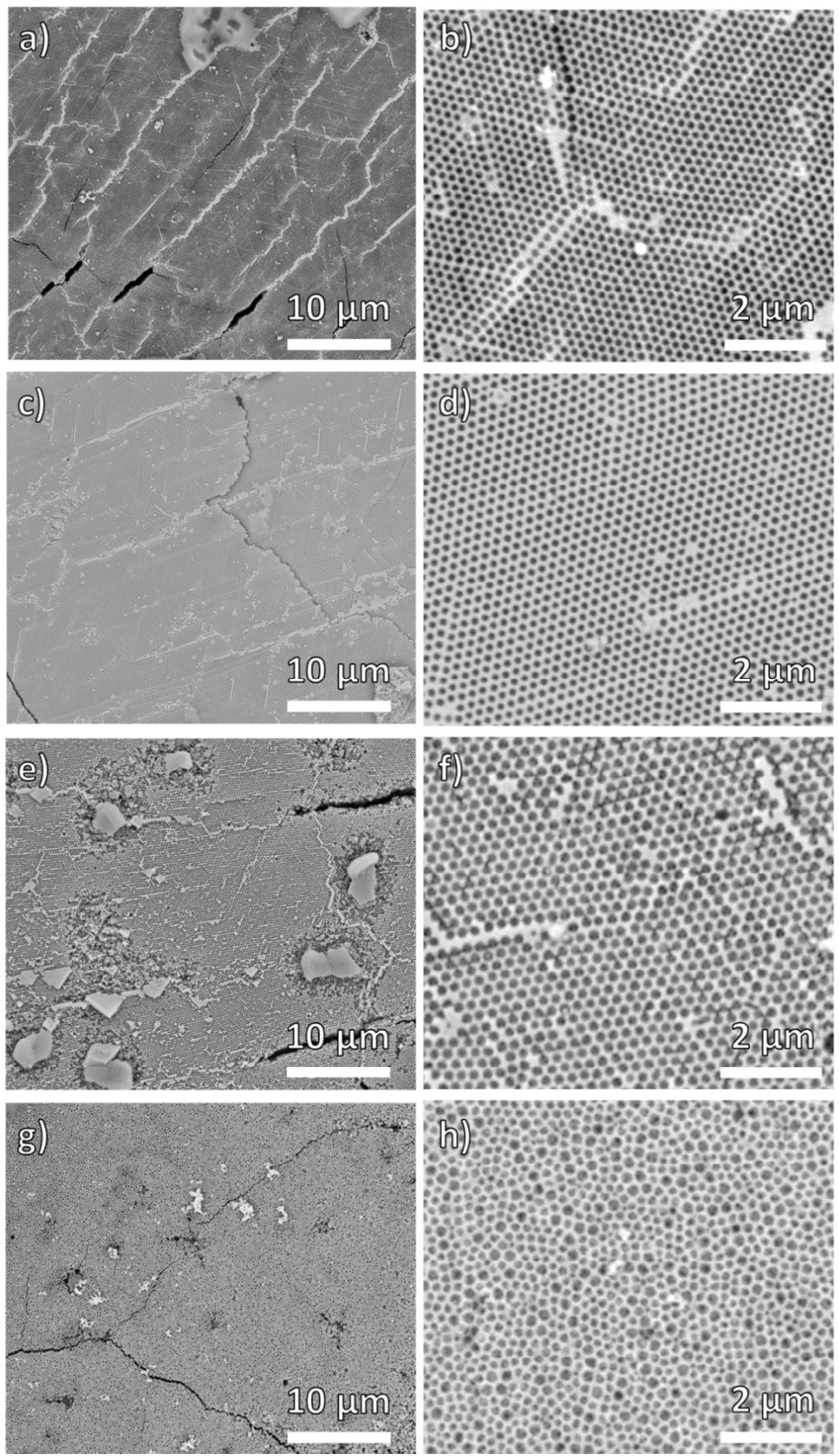

Figure S4: Representative SEM images of 205-MAPbBr $3(\mathrm{a}, \mathrm{b}), 220-\mathrm{MAPbBr}_{3}$

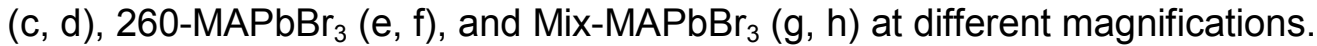



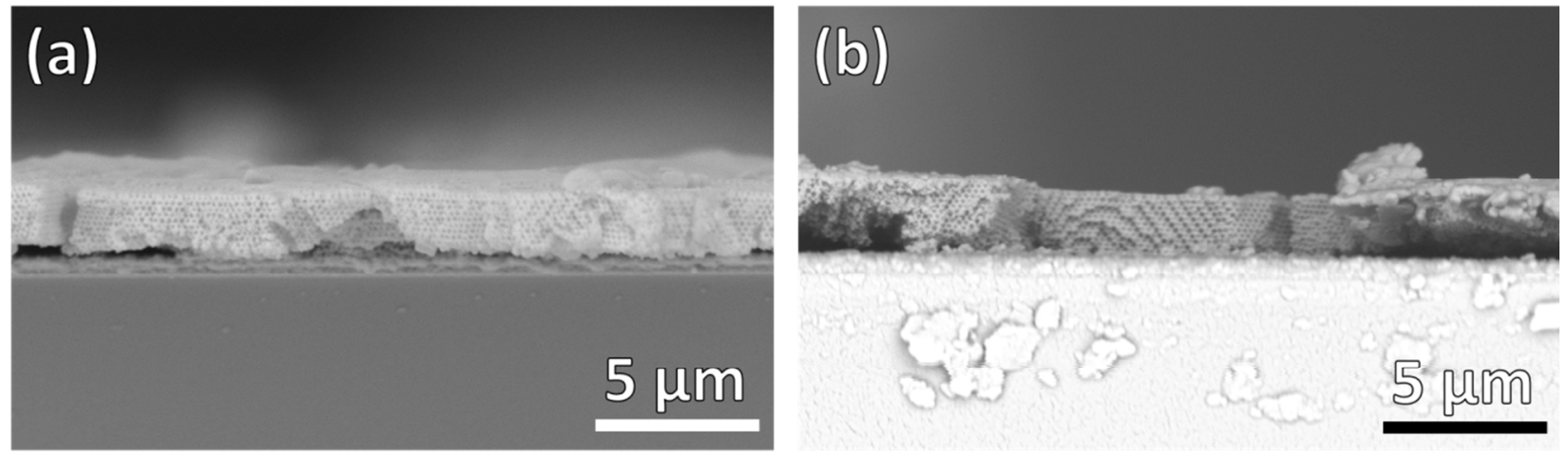

Figure S5: Cross section SEM of 220-MAPbBr 3 deposited on FTO (a) and $\mathrm{TiO}_{2}$ (b).

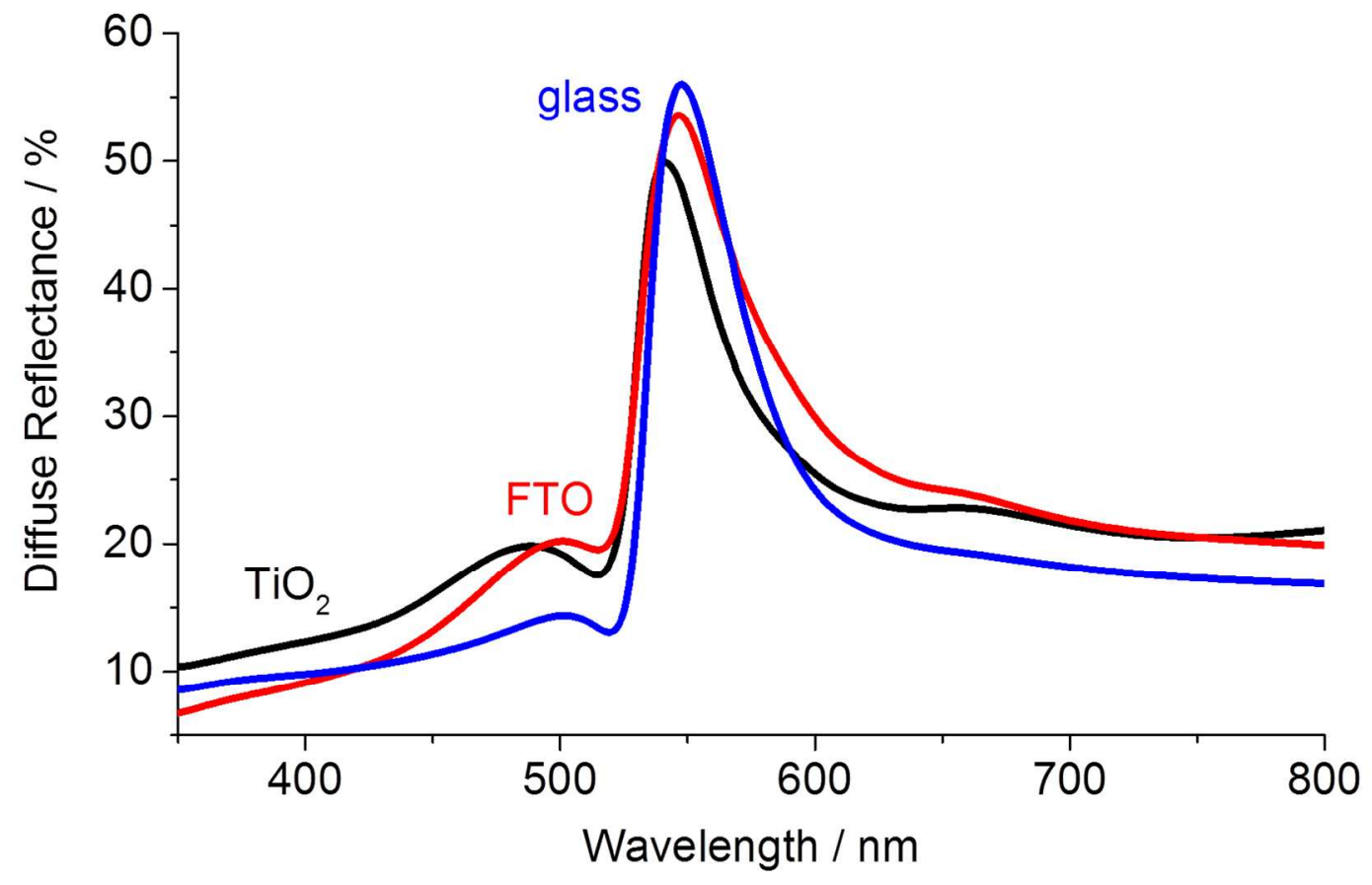

Figure S6: Diffuse reflectance spectrum of 220-MAPbBr 3 prepared on glass, $\mathrm{FTO}$, and $\mathrm{TiO}_{2}$ deposited on FTO. 

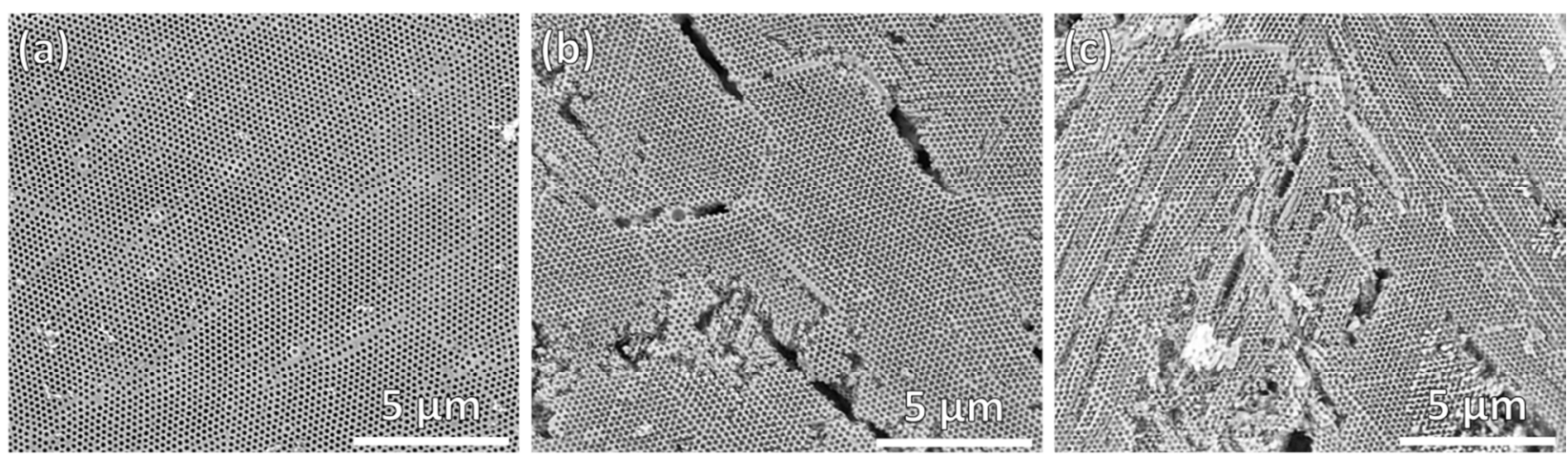

Figure S7: Representative SEM images of 220-MAPbCl ${ }_{3}(\mathrm{a}), 220-\left.\mathrm{MAPbCl}_{1.5}\right|_{1.5}$ (b), and $220-\mathrm{MAPbl}_{3}$ (c). 